\title{
Analisis Pengetahuan Konseptual, Prosedural, dan Metakognitif Siswa Melalui Pembelajaran Integrasi Flipped Classroom dan PBL
}

\author{
H. Bintang 1, E. Darnah ${ }^{2}$, N. Masta ${ }^{1}$, Rinaldi², T. Guswantoro' ${ }^{1}$, dan M. \\ Sianturi ${ }^{1}$ \\ ${ }^{1}$ Program Studi Pendidikan Fisika, Universitas Kristen Indonesia \\ ${ }^{2}$ Sekolah Menengah Atas Negeri 37 Jakarta, Indonesia \\ *Email: ngia.masta@uki.ac.id
}

Received: June 13 ${ }^{\text {th }}$, 2020. Accepted: August 19th 2020. Published: August 31 ${ }^{\text {st }}, 2020$

\begin{abstract}
Abstrak
Pembelajaran berfokus pada siswa adalah sebuah pendekatan pembelajaran yang tidak sekedar berbasis pada keaktifan siswa dalam memeroleh pengetahuan konseptual secara mandiri, namun hingga mencapai tahap penerapan di kehidupan seharihari dalam bentuk pengetahuan prosedural dan metakognitif. Model pembelajaran flipped classroom mampu mengaktifkan siswa untuk dapat belajar mandiri sebelum pembelajaran tatap muka di kelas. Problem Based Learning (PBL) adalah model pembelajaran yang menginisiasi siswa untuk mengaplikasikan pengetahuan yang dimilikinya dalam pemecahan masalah. Flipped classroom maupun PBL merupakan model pembelajaran yang mengkondisikan siswa untuk aktif mengkonstruksi pengetahuan secara mandiri dan memicu keingintahuan dalam penyelesaian masalah. Tujuan penelitian ini adalah untuk menganalisis perbedaan persentase pengetahuan konseptual, prosedural, dan metakognitif antara kelas yang mendapat perlakuan integrasi model flipped classroom dan PBL dengan kelas kontrol pada materi Gerak Lurus. Jenis penelitian ini adalah kuasi eksperimen berbentuk post test only kontrol design. Populasi dalam penelitian ini adalah seluruh siswa kelas X MIPA SMA Negeri 37 Jakarta pada tahun ajaran 2019-2020. Sampel dalam penelitian ini adalah siswa kelas X MIPA 1 sebagai kelas eksperimen dan siswa kelas X MIPA 2 sebagai kelas kontrol. Pengambilan sampel dilakukan menggunakan teknik cluster sampling. Hasil penelitian yang diperoleh menunjukkan
\end{abstract}


persentase pengetahuan konseptual, prosedural dan metakognitif kelas eksperimen masing-masing 88,9\%;77,8\%; dan $88,9 \%$ yang lebih tinggi dibanding kelas kontrol dengan persentase masing-masing 66,7\%; 55,8\%; dan 75\%. Integrasi model flipped classroom dan PBL dapat diterapkan pada materi selain Gerak Lurus untuk meningkatkan pengetahuan konseptual, prosedural, dan metakognitif.

\begin{abstract}
Student-centered learning (SCL) is a learning approach that not only encourages to how student constructs their conceptual knowledge, but also to achieve the involvement of their knowledge in daily activity, in forms procedural and metacognitive knowledge. Flipped classroom learning models marked by reversed learning activities syntax between class and home, which promoted student to active self-learning, before turn into face to face class meeting. Problem Based Learning (PBL) model provides students to apply their knowledge to formulate strategy and solution in facing their problem. Flipped classroom or PBL, both are student-centered learning models that triggers student to self-constructed knowledge actively and student's curiosity to solve their problem. This paper attempts to analyze the influence of integration flipped classroom and PBL on conceptual, procedural, and metacognitive knowledge on Linear Motion subject. This research is a quasi experimental model with post-test only control design. The population in this study were all students of class X MIPA SMA Negeri 37 Jakarta in the 2019-2020 school year. The sample in this study were students of class X MIPA 1 as the experimental class and class $X$ MIPA 2 as the control class. The sample was taken using cluster sampling technique. The results obtained showed that the percentage of conceptual, procedural and metacognitive knowledge of the experimental class was $88.9 \%$; $77.8 \%$; and $88.9 \%$ which is higher than the control class with the respective percentage $66.7 \%$; $55.8 \%$; and $75 \%$. The integration of the flipped classroom and PBL models can be applied to materials other than Linear Motion to improve conceptual, procedural, and metacognitive knowledge. @2020PERJ
\end{abstract}

Keywords: Flipped classroom; Problem Based Learning; conceptual knowledge; procedural knowledge; metacognitive knowledge. 


\section{PENDAHULUAN}

Pergeseran fokus pembelajaran dari guru kepada siswa muncul sebagai jawaban atas kurangnya keaktifan siswa dalam pembelajaran (Kiernan, Ledwith, \& Lynch, 2017), ketidakmandirian siswa dalam mengkonstruksi pengetahuan (Olusegun, 2015), dan kegagapan siswa dalam mengaplikasikan pengetahuan dalam kehidupan sehari-hari (Van Vliet, Winnips, \& Brouwer, 2015). Pembelajaran berfokus pada siswa adalah sebuah pendekatan pembelajaran yang menunjukkan proses konstruksi pengetahuan secara mandiri (Widari \& Jazadi, 2019), pelibatan aktif secara utuh (Antika, 2014), dan kontekstual (Haryanto \& Arty, 2019; Tari \& Rosana, 2019). Oleh karena itu, seluruh aktivitas dalam pembelajaran dirancang agar siswa dapat menggali dan meramu pengetahuan secara mandiri dan aktif dalam aspek kognitif, psikomotorik, dan afektif. Peran guru dalam pembelajaran yang berpusat pada siswa bukan lagi sebagai pengajar, namun menjadi fasilitator dan motivator (Klemenčič, 2017; Oinam, 2017; Serin, 2018). Guru harus berinovasi dalam menyediakan lingkungan dan kondisi yang mendukung proses terjadinya konstruksi pengetahuan secara aktif dan mandiri dalam diri siswa (Fariyani et al., 2020). Guru menyediakan sumber belajar yang dapat diakses dan dipahami dengan lebih mudah oleh siswa. Guru juga harus dapat mempersiapkan kondisi yang kondusif agar siswa dapat meramu pengetahuan yang diperolehnya untuk diaplikasikan dalam penyelesaian masalah. Apabila siswa mengalami kesulitan maka guru dapat memberikan bantuan dengan cara berdialog untuk mengarahkan siswa dalam bentuk pertanyaan penuntun atau petunjuk yang dapat memancing siswa untuk menentukan strategi pemecahan masalahnya sendiri (Tuwoso, 2016).

Pembelajaran adalah proses yang menentukan berhasil atau tidaknya pendidikan sehingga harus didesain agar dapat terlaksana secara efektif dan efisien. Pembelajaran yang efektif dan efisien ditandai dengan keaktifan siswa dalam mengkonstruksi pengetahuan hingga dapat menunjukkan perubahan dalam pengetahuan, sikap, dan keterampilan sesuai tahapan perkembangannya (Dewi \& Nur, 2014).

Wujud penyediaaan lingkungan dan kondisi yang kondusif bagi proses konstruksi pengetahuan siswa adalah dengan menyelenggarakan pembelajaran yang dapat dilakukan di manapun dan kapanpun. Setiap siswa memiliki jam belajar optimal yang berbeda-beda, misalnya siswa A lebih optimal jika belajar di pagi hari, sementara siswa B lebih optimal di malam hari. Tempat belajar yang optimal bagi siswa juga dapat berbeda-beda, misalnya siswa A lebih optimal jika belajar di 
sekolah, sementara siswa B lebih optimal jika belajar di rumah. Guru dapat menyiapkan bahan ajar berbasis digital yang dapat diakses baik secara online maupun offline untuk dapat mengakomodasi kebutuhan siswa yang berbedabeda tersebut. Bahan ajar online memanfaatkan teknologi informasi yang digunakan dalam bentuk $e$ learning. Pembelajaran dalam bentuk e-learning dapat memfasilitasi siswa untuk secara mandiri belajar dimana saja dan kapan saja, selama siswa dapat terhubung dengan jaringan internet.

Selama proses konstruksi pengetahuan siswa secara personal melalui interaksi dengan lingkungan, ditemukan fakta bahwa konsepsi yang dihasilkan oleh siswa masih keliru, yaitu belum sesuai dengan konsepsi para ahli (Fariyani et al., 2017). Ketidaksesuaian konsepsi siswa dengan konsep para ahli dapat disebabkan karena pengetahuan yang diperoleh masih dalam bentuk potongan-potongan (chunky) yang belum dapat dihubungkan satu sama lain. Fenomena seperti ini dapat terlihat dari cara siswa mengaplikasikan pengetahuannya secara inkonsisten, bergantung pada konteks masalah yang dihadapinya (Taqwa \& Pilendia, 2018). Pembelajaran mandiri pada siswa perlu dilanjutkan dengan tahapan interaksi langsung dengan guru agar dapat menghindari miskonsepsi siswa. Pada tahapan lanjutan ini pembelajaran yang dilakukan tidak untuk menjabarkan materi; tetapi untuk meluruskan konsepsi-konsepsi yang keliru, melakukan pengayaan atau pendalaman, melakukan kegiatan percobaan, melakukan pemecahan masalah, atau mengerjakan proyek.

PBB menyatakan terdapat lima keterampilan yang diperlukan pada abad 21 dalam membangun masyarakat dunia yang cerdas, antara lain: (1) melek teknologi informasi dan media digital; (2) berpikir kritis; (3) pemecahan masalah; (4) komunikasi efektif; (5) kolaborasi dan membangun jaringan (Anriani \& Fathurrohman, 2019). Guru dapat mengimplementasikan model flipped classroom untuk mengoptimalkan pencapaian lima keterampilan tersebut.

Model flipped classroom membuat siswa mengalami pembelajaran online dan offline. Tahap online dilakukan di rumah dan tahap offline dilakukan di kelas. Tahap online dilakukan sebelum siswa melakukan tahap offline. Pada tahap online, siswa menggunakan platform Learning Management System (LMS) dan belajar menggunakan bahan ajar berbasis digital, misalnya buku elektronik, video pembelajaran, dan kuis online. Pada tahap offline siswa akan berdiskusi, mengerjakan eksperimen, proyek, atau tugas bersama kelompok, serta menyusun dan melakukan presentasi.

Pada tahap online, siswa dapat mengasah keterampilan melek teknologi informasi dan media 
digital. Pada tahap offline, siswa dapat mengasah keterampilan berkomunikasi, berkolaborasi, dan membangun jaringan. Keterampilan berpikir kritis dan pemecahan masalah dapat dimodifikasi untuk dimaksimalkan pada tahap online dan offline. Berdasarkan penjelasan tersebut, model pembelajaran flipped classroom adalah salah satu model pembelajaran yang relevan diterapkan untuk pembelajaran abad 21.

Pembelajaran berpusat pada siswa tidak hanya untuk memfasilitasi siswa menggali dan meramu pengatahuan secara personal, namun juga harus dapat memfasilitasi siswa untuk memeroleh pengetahuan konseptual, prosedural, dan metakognitif. Implementasi model flipped classroom dapat meningkatkan kemampuan metakognitif siswa (Van Vliet et al., 2015), termasuk kemampuan metacognitive pada pembelajaran fisika (Umam, 2013). Procedural knowledge pada siswa juga dapat mengalami peningkatan setelah diberikan model flipped classroom (Chen, Liou, \& Chen, 2019).

Model pembelajaran berbasis masalah (PBL) adalah model pembelajaran yang dicirikan dengan tersedianya permasalahan kontekstual yang menantang untuk diselesaikan oleh siswa (Peranginangin, Saragih, \& Siagian, 2019). Model PBL dapat dengan mudah dimodifikasi untuk dikombinasikan dengan model atau pendekatan pembelajaran yang lain. Model ini didesain agar dapat digunakan pada mata pelajaran dan kelas apapun, mulai dari sekolah dasar hingga perguruan tinggi. Model PBL sangat sesuai dengan paham konstruktivisme dan memiliki sintaks yang lengkap dalam melakukan pembelajaran saintifik (Klemenčič, 2017; Singhal, 2017), mulai dari mengidentifikasi, menyelesaikan, mengkomunikasikan pemecahan masalah yang diperoleh. Pelaksanaan model PBL dimulai dari guru/fasilitator yang memberikan masalah sesuai topik pembelajaran, kemudian siswa dalam kelompok berkolaborasi dalam pemecahan masalah. Setelah berdiskusi kelompok, siswa mengkomunikasikan hasil kolaborasinya dalam bentuk presentasi dan diskusi kelas. Proses tersebut dapat melatih siswa untuk berkomunikasi secara efektif dalam menjelaskan hal yang telah dikerjakan.

Pembelajaran flipped classroom yang dikombinasikan dengan PBL banyak diterapkan dalam pendidikan tinggi, khususnya di bidang pendidikan kedokteran (Hu et al., 2019). Namun kombinasi pembelajaran flipped classroom dengan PBL pada jenjang pendidikan menengah terutama di Indonesia masih sangat jarang ditemukan. Penelitian tentang implementasi flipped classroom yang dikombinasikan dengan Problem Based Learning baru ditemukan pada 
peminatan Matematika dan IPA di Sekolah Menengah Atas (SMA), di antaranya pada pembelajaran matematika (Ramadhani, Umam, Abdurrahman, \& Syazali, 2019), biologi (Melyana, 2018) dan fisika (Damayanti, Santyasa, Sudiatmika, 2020). Implementasi flipped classroom yang dikombinasikan dengan PBL dalam pembelajaran fisika masih sangat terbatas, di antaranya yang telah dilakukan oleh Putri (2018) dan Arnata, Mardana, \& Suwindra (2020). Integrasi model flipped classroom dan PBL masih terbatas sehingga perlu untuk dikembangkan dan diteliti pengaruhnya dalam pembelajaran fisika.

Berdasarkan uraian yang telah dijelaskan, diperlukan model pembelajaran yang memadukan tahap pembelajaran mandiri dan dilanjutkan dengan tahap pendalaman untuk memecahkan masalah. Salah satu model pembelajaran yang memfasilitasi siswa untuk aktif dalam proses pembelajaran melalui pembelajaran mandiri adalah model pembelajaran flipped classroom (Subagia, 2017). Oleh karena itu, integrasi flipped classrom dan PBL diharapkan dapat menyediakan kondisi dan lingkungan yang kondusif bagi siswa untuk memeroleh, meramu, memaknai pengetahuan secara personal, dan menumbuhkan kemandirian belajar. Penelitian ini bertujuan untuk menganalisis perbedaan persentase pengetahuan konseptual, prosedural dan metakognitif antara kelas yang mendapat perlakuan berupa integrasi model flipped classroom dan PBL dengan kelas kontrol pada materi Gerak Lurus.

\section{METODE}

Penelitian ini merupakan penelitian kuasi eksperimen dengan desain Post-Test Only Control Design. Penelitian ini menggunakan dua jenis kelas, yaitu kelas kontrol dan kelas eksperimen. Kelas kontrol adalah kelas yang tidak diberi perlakuan, sementara kelas eksperimen adalah kelas yang diberi perlakuan berupa integrasi model flipped classroom dan PBL dalam pembelajaran materi Gerak Lurus.

Populasi dalam penelitian ini adalah seluruh siswa kelas X MIPA SMA Negeri 37 Jakarta. Sampel dalam penelitian ini adalah dua dari empat kelas X MIPA SMA Negeri 37, yaitu kelas X MIPA 1 dan kelas $X$ MIPA 2. Kelas X MIPA 1 adalah kelas eksperimen dengan jumlah sampel sebanyak 35 siswa. Kelas $X$ MIPA 2 adalah kelas kontrol yang tidak diberi perlakuan, sejumlah 35 siswa.

Variabel terikat dalam penelitian ini adalah pengetahuan konseptual, prosedural, dan metakognitif sesuai revisi taksonomi Bloom oleh Anderson (Şanli, 2019; Wilson, 2016). Batasan dan uraian dari masing-masing variabel terikat dalam penelitian ini diberikan pada Tabel 1. 
Tabel 1. Deskripsi variabel terikat dalam penelitian

\begin{tabular}{|c|c|c|}
\hline \multicolumn{2}{|r|}{ Pengetahuan } & \multirow[t]{2}{*}{ Kode } \\
\hline Tipe & Sub Tipe & \\
\hline \multirow[t]{2}{*}{ Konseptual } & Pengetahuan prinsip dan generalisasi & $\mathrm{Bb}$ \\
\hline & $\begin{array}{l}\text { 1. Pengetahuan subjek khusus dan } \\
\text { algoritma }\end{array}$ & $\mathrm{Ca}$ \\
\hline \multirow[t]{2}{*}{ Prosedural } & 2. Pengetahuan teknik dan metode & $\mathrm{Cb}$ \\
\hline & $\begin{array}{l}\text { 3. Pengetahuan kriteria penentuan langkah } \\
\text { penyelesaian }\end{array}$ & Cc \\
\hline Metakognitif & Pengetahuan strategi & $\mathrm{Da}$ \\
\hline
\end{tabular}

Instrumen penelitian yang digunakan adalah tes tertulis berupa post-test berbentuk pilihan ganda untuk pengetahuan konseptual, pilihan ganda dengan alasan terbuka (open ended question) untuk mengetahui pengatahuan prosedural dan bentuk esai untuk mengetahui tingkat pengetahuan metakognitif. Hasil jawaban benar kemudian dirata-rata dan dibuat dalam bentuk persentase. Nilai persentase tersebut selanjutnya direkapitulasi dalam bentuk grafik dan tabel perbandingan tingkat pengetahuan konseptual, prosedural, dan metakognitif kelas kontrol dan kelas eksperimen.

Perangkat pembelajaran dalam penelitian disusun sesuai dengan integrasi model flipped classroom dan PBL, berupa: (1) Rencana pelaksanaan pembelajaran (RPP) dengan sintaks integrasi model flipped classroom dan PBL (Tabel 2); (2) Lembar Kerja Siswa (LKS); (3)
Modul pembelajaran Gerak Lurus; (4) Lembar Kerja praktikum; (5) Learning Management System (LMS); dan (6) Platform Quizizz untuk kuis online.

\section{HASIL DAN PEMBAHASAN}

Integrasi flipped classroom dan Problem Based Learning (PBL)

Pelaksanaan integrasi flipped classroom dan Problem Based Learning (PBL) sebagaimana disajikan pada Gambar 1 menunjukkan penelitian ini didesain untuk dua hingga tiga pertemuan kelas. Apabila siswa belum terbiasa menggunakan Learning Management System (LMS), maka beberapa hari sebelumnya harus dilakukan sosialisasi penggunaan LMS kepada siswa yang disertai penjelasan pelaksanaan pembelajaran. Siswa perlu memahami hal-hal yang perlu dilakukan sebelum, saat, dan setelah pelaksanaan tatap muka di kelas (Irawati et al., 2019). 
Tabel 2. Deskripsi sintaks integrasi flipped classroom dan PBL

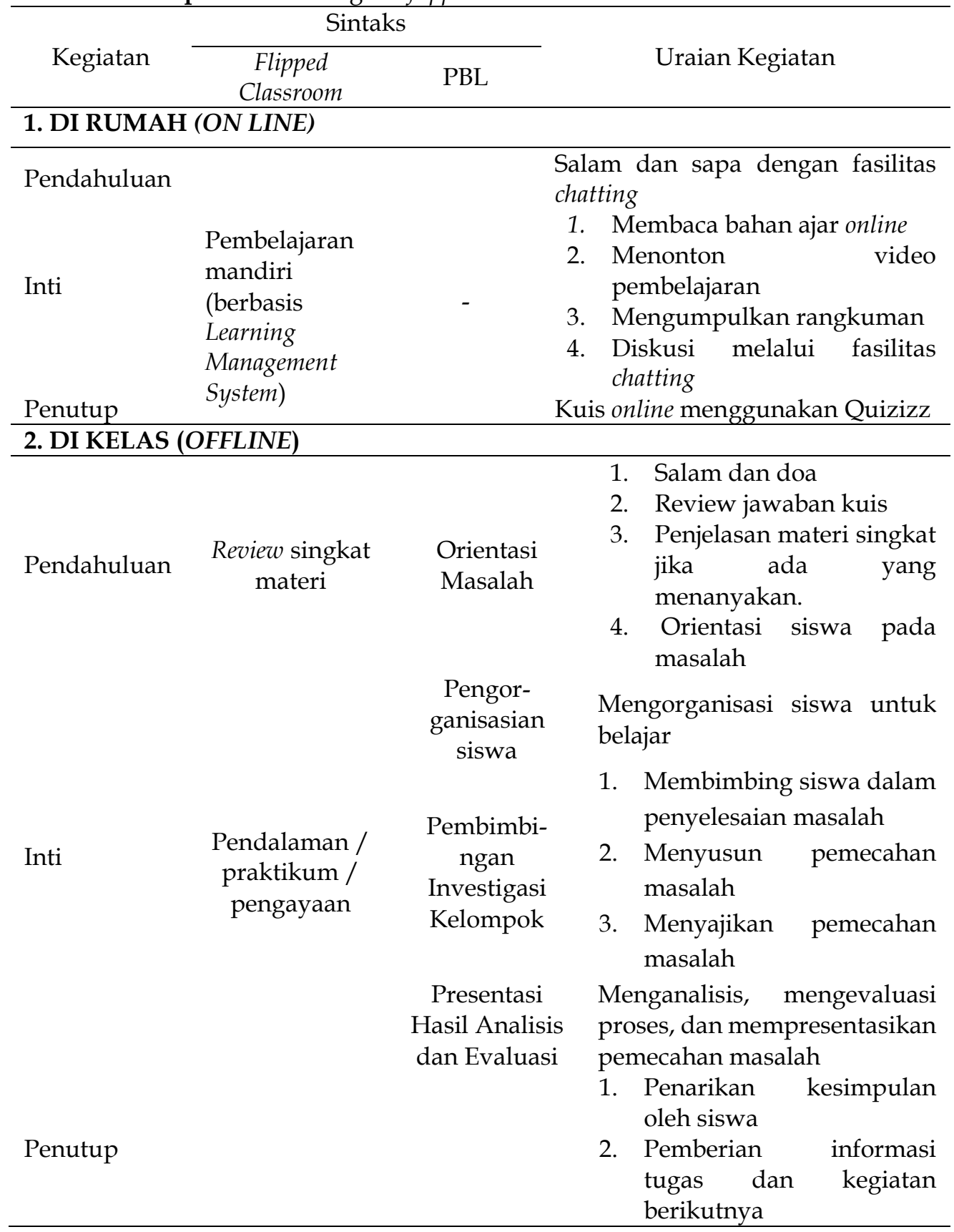




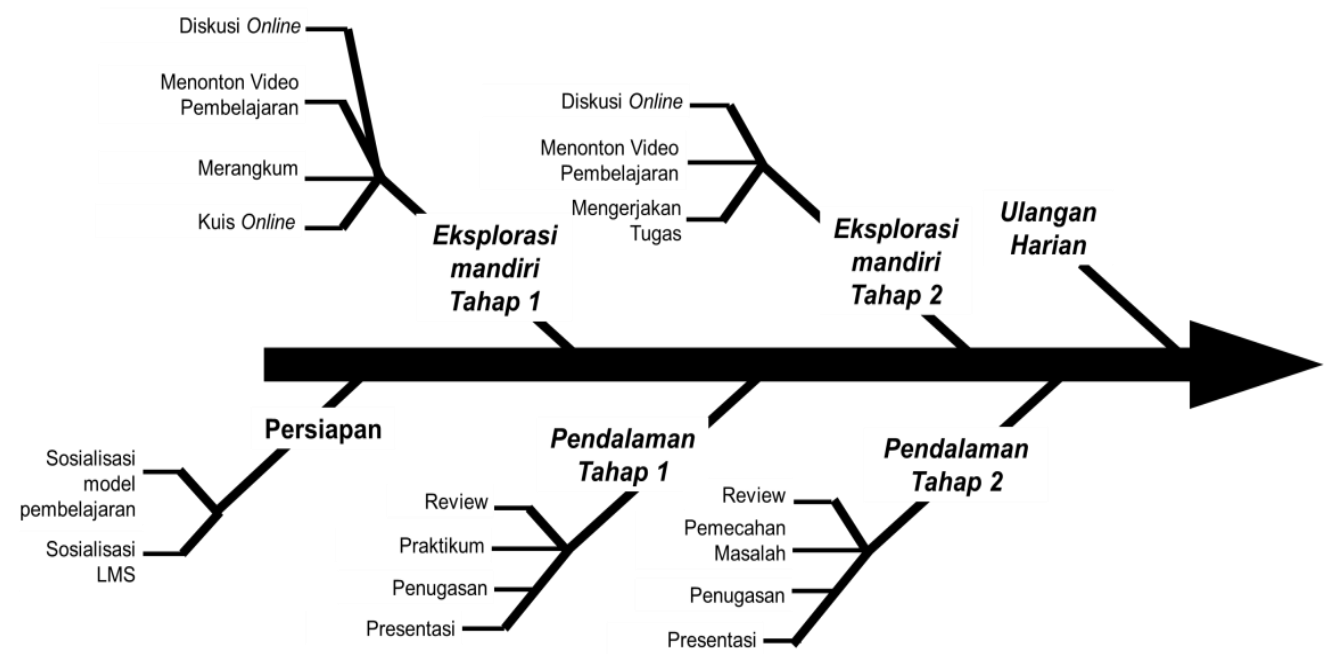

Gambar 1. Diagram pelaksananaan integrasi flipped classroom dan PBL dalam pembelajaran pada materi Gerak Lurus.

Penerapan flipped classroom dalam pembelajaran dilakukan dalam dua bagian, yaitu eksplorasi mandiri (online) dan pendalaman materi (offline). Kegiatan merangkum dan kuis online dilakukan untuk mengantisipasi siswa yang mengabaikan kegiatan online. Pembimbingan secara online maupun offline dilakukan untuk mengatasi miskonsepsi dan kesulitan belajar siswa (Fariyani et al., 2017). Pembimbingan secara online dilakukan melalui fasilitas chatting yang tersedia di LMS atau platform media sosial lainnya sesuai kesepakatan antara siswa dan guru. Pembimbingan offline terjadi di kelas dalam bentuk pendalaman, praktikum, atau pengayaan yang selalu disertai dengan teknik pembelajaran kelompok dan presentasi.

\section{Pengetahuan Konseptual}

Pengetahuan konseptual ditunjukkan dengan kemampuan menghubungkan antar elemen penyusun sehingga membentuk sebuah konsep. Seseorang dikatakan dapat membedakan suatu konsep dengan konsep lainnya apabila telah berhasil menggeneralisasi komponen pengetahuan penyusun konsep sebelumnya (Van Vliet, Winnips, \& Brouwer, 2015). Proses generalisasi komponen pengetahuan ditandai dengan berlangsungnya identifikasi terhadap hal-hal yang ingin dibedakan dan selanjutnya akan dicocokkan dengan pengetahuan-pengetahuan yang telah dimiliki sebelumnya. Apabila komponen-komponen identifikasi sudah sesuai dengan pengetahuan awal, maka seseorang akan dapat mengenali sebuah konsep. 
Pengetahuan konseptual tentang Gerak Lurus dapat dibagi menjadi dua, yaitu Gerak Lurus Beraturan dan Gerak Lurus Berubah Beraturan. Konsep Gerak Lurus pada penelitian ini diuji menggunakan instrumen tes berupa pilihan ganda yang memberikan empat pernyataan tentang konsep perpindahan, kecepatan, percepatan pada Gerak Lurus Beraturan (GLB) dan Gerak Lurus Berubah Beraturan (GLBB). Siswa kemudian diminta untuk memilih pernyataan yang sesuai dengan Gerak Lurus Beraturan (Gambar 2.a) dan Gerak Lurus Berubah Beraturan (Gambar 2.b).

Persentase jawaban benar terhadap butir soal pengetahuan konseptual menunjukkan adanya perbedaan kemampuan siswa dalam membedakan konsep Gerak Lurus Beraturan dan Gerak Lurus Berubah Beraturan (Gambar 3) antara kelas eksperimen dengan kelas kontrol.

Kelas eksperimen memiliki rerata persentase lebih tinggi dibanding kelas kontrol, baik pada konsep GLB maupun GLBB. Persentase jawaban benar pada konsep GLB yaitu 77,8\% pada kelas eksperimen dan 55,6\% pada kelas kontrol; sedangkan jawaban benar pada GLBB adalah 66,7\% pada kelas eksperimen dan $44,4 \%$ pada kelas kontrol. Persentase jawaban benar pada kelas eksperimen yang lebih tinggi dibanding kelas kontrol merepresentasikan pengaruh integrasi flipped classroom dan PBL dalam pembelajaran. Proses pembelajaran mandiri, pembimbingan, dan penguatan yang dialami selama pembelajaran menghasilkan pengalaman belajar kompleks dan mendalam (Azizah et al., 2019). Pengalaman belajar ini kemudian mendukung keberhasilan pembelajaran yang terlihat dari pengetahuan konseptual.
a. Soal GLB
(Pengetahuan Konseptual (Bb))
Perhatikan pernyataan berikut:
(1) Kecepatan benda tidak mengalami perubahan.
(2) Percepatan benda tidak mengalami perubahan.
(3) Gradien grafik v- t adalah nol
(4) Grafik s-t menunjukkan kurva parabola
Pernyataan yang benar tentang GLB adalah …
a. (1), (2), dan (3)
b. (1) dan (3)
D. (4) saja
c. (2) dan (4)
E. semua benar

(a)

\section{b. Soal GLBB \\ (Pengetahuan Konseptual (Bb))}

Perhatikan pernyataan berikut:

(1) Kecepatan benda tidak mengalami perubahan.

(2) Percepatan benda tidak mengalami perubahan.

(3) Gradien grafik v- t adalah nol

(4) Grafik s-t menunjukkan kurva parabola. Pernyataan yang benar tentang GLBB adalah ....
a. (1), (2), dan (3)
b. (1) dan (3)
D. (4) saja
c. (2) dan (4)
E. semua benar

(b)

Gambar 2. Butir soal pada instrumen tes untuk menguji kemampuan (a) Gerak Lurus Beraturan; (b) Gerak Lurus Berubah Beraturan. 


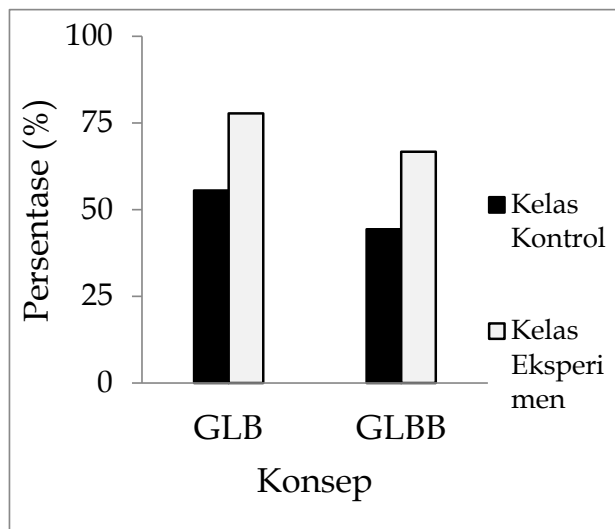

Gambar 3. Hasil analisis pengetahuan konseptual kelas kontrol dan kelas eksperimen.

\section{Pengetahuan Prosedural}

Kemampuan menyusun atau melakukan suatu solusi (kemampuan prosedural) adalah suatu kesanggupan untuk menyusun uraian pemikiran dalam bentuk langkah- langkah sistematis dan tepat untuk menyelesaikan permasalahan. Kemampuan ini diperlukan dalam penyelesaian masalah yang terdiri atas beberapa tahapan jawaban atau berupa uraian langkah-langkah. Siswa diberikan permasalahan yang memerlukan kombinasi dari beberapa konsep agar dapat menunjukkan kemampuan penyusunan solusi.

Saat tatap muka berlangsung, terlihat siswa mengalami kesulitan atau kebingungan saat berhadapan dengan permasalahan yang lebih kompleks. Permasalahan kompleks yang diberikan akan mendorong siswa untuk mengkolaborasikan pengetahuan-pengetahuan yang telah diperoleh. Pada kelas eksperimen, kesulitan belajar lebih awal terlihat karena siswa telah memelajari topik terlebih dahulu di rumah melalui modul ajar, video, dan membuat rangkuman. Namum kesulitan tersebut juga diatasi lebih awal karena siswa diberikan bantuan berupa pembimbingan (offline dan online) dan review materi. Pembelajaran yang dilakukan di kelas juga tidak lagi membahas/mengeksplorasi materi, namun sampai ke tahapan pendalaman materi. Pendalaman yang dilakukan pada penelitian ini adalah dalam bentuk diskusi pemecahan masalah dan praktikum. Kegiatan pembelajaran yang terjadi pada integrasi model flipped classroom dan PBL menghasilkan pengalaman belajar yang lebih tinggi dan frekuensi belajar lebih banyak (Chen, Liou, \& Chen, 2019).

Pada penelitian ini, untuk menggali pengetahuan prosedural digunakan butir soal berupa pilihan ganda yang memuat sebuah permasalahan Gerak Lurus Beraturan dan Gerak Lurus Berubah Beraturan (Gambar 4.a), namun siswa juga diminta untuk menuliskan uraian jawaban agar dapat diketahui pengetahuan prosedural dalam bentuk pengetahuan subjek khusus dan algoritma (Ca), pengetahuan teknik dan metode $(\mathrm{Cb})$, serta pengetahuan tentang kriteria untuk menentukan langkah-langkah penyelesaian (Cc). 


\section{a. Soal (Pengetahuan Prosedural)}

Sebuah mobil mulai bergerak dari keadaan diam dengan percepatan $0,2 \mathrm{~m} / \mathrm{s}^{2}$ dalam waktu 2 menit. Kemudian mobil bergerak dengan kecepatan konstan $24 \mathrm{~m} / \mathrm{s}$ selama 5 menit. Sesudah itu mobil tersebut direm dengan perlambatan $1,5 \mathrm{~m} / \mathrm{s}^{2}$ sampai akhirnya berhenti. Jarak total yang ditempuh mobil adalah ....
A. $7779 \mathrm{~m}$
D. $8832 m$
B. $8111 \mathrm{~m}$
E. $8632 m$
C. $8640 \mathrm{~m}$

(a)

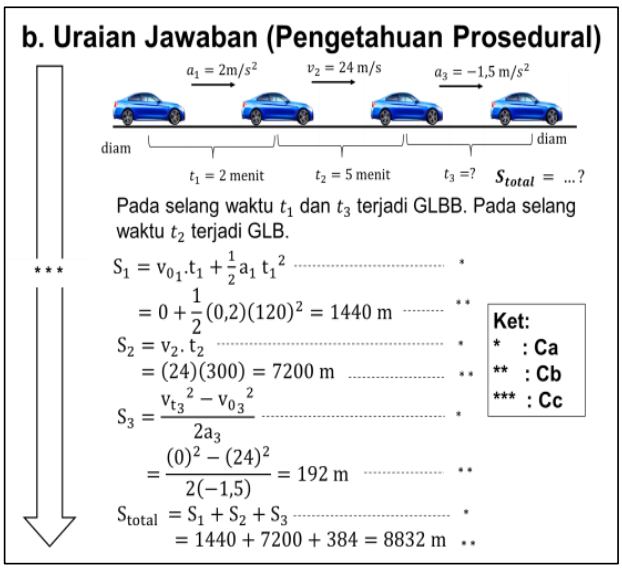

(b)

Gambar 4. (a) Butir soal Gerak Lurus untuk melihat pengetahuan prosedural; (b) Uraian jawaban pengetahuan prosedural.

Butir soal ini meminta siswa untuk dapat menentukan jarak total dari sebuah mobil yang geraknya dapat dibagi kedalam 3 tahapan. Tahapan pertama terjadi pada selang waktu $t_{1}$, pada interval ini mobil bergerak dari keadaan awal diam kemudian dipercepat. Tahapan ke dua terjadi pada interval $t_{2}$, pada tahapan ini mobil bergerak dengan kecepatan konstan dan pada interval ke tiga $\left(t_{3}\right)$ mobil bergerak maju dengan mesin direm hingga berhenti (Gambar 4.b). Anak panah yang berarah ke bawah menggambarkan alur penyelesaian masalah, yang dapat dibagi dalam empat langkah, yaitu: pengidentifikasian masalah; pembagian masalah ke dalam tahapan-tahapan; (3) penyelesaian setiap tahapan masalah; dan (4) penyelesaian masalah secara umum.

Hasil rekapitulasi persentase kemampuan prosedural siswa kelas eksperimen dan kontrol disajikan pada Gambar 5. Selisih persentase paling besar terlihat pada komponen $\mathrm{Ca}$ dan selisih paling kecil terlihat pada komponen $\mathrm{Cc}$.

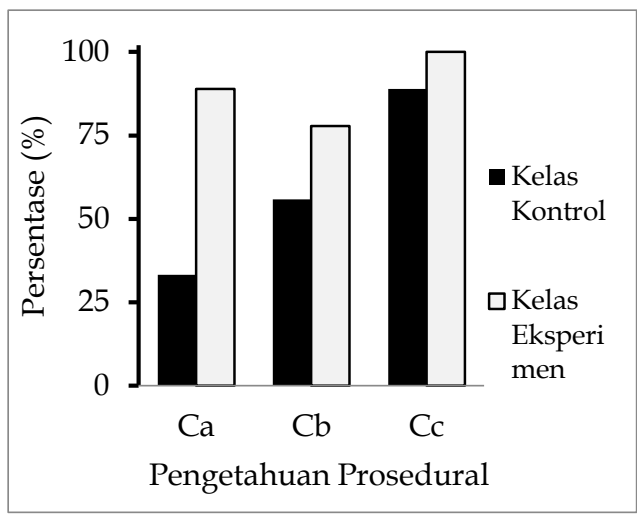

Gambar 5. Rekapitulasi persentase pengetahuan prosedural $(\mathrm{Ca}, \mathrm{Cb}$, dan Cc) pada kelas kontrol dan kelas eksperimen.

Selisih persentase yang besar pada komponen $\mathrm{Ca}$ menunjukkan bahwa rata-rata siswa di kelas eksperimen cenderung menyajikan penyelesaian masalah dengan menuliskan algoritma berupa persamaan-persamaan atau simbolsimbol yang sesuai dengan tahapan 
penyelesaian masalah. Pada kelas kontrol, siswa cenderung melompati tahapan penulisan persamaan matematis ini dan langsung menuliskan angka saja. Selisih persentase yang cenderung kecil pada komponen CC menunjukkan baik pada kelas kontrol maupun kelas eksperimen menunjukkan mayoritas siswa telah memiliki kemampuan penyelesaian masalah dengan prosedur yang sistematis.

\section{Pengetahuan Metakognitif}

Pengetahuan metakognitif ditunjukkan melalui kesadaran seseorang untuk menerapkan pengetahuan dalam kehidupan sehari-hari. Pengetahuan yang telah dimiliki oleh siswa harus mengalami proses pengaktifan agar pengetahuan tersebut dapat disimpan dalam memori jangka panjang siswa. Cara mengaktifkan pengetahuan adalah dengan memodifikasi lingkungan belajar yang mendorong siswa untuk menyusun strategi dalam menghadapi permasalahan yang kontekstual.

Pada penelitian ini, permasalahan kontekstual yang digunakan untuk melihat pengetahuan metakognitif siswa adalah fenomena kecelakaan yang sering terjadi di jalan tol Cipularang $\mathrm{km}$ 90. Pada saat pembelajaran, siswa merasa tertarik untuk mempelajari fenomena tersebut dari sudut pandang saintifik karena masyarakat sering mengaitkan kecelakaan di $\mathrm{km} 90$ dengan faktor mistis atau gaib. Fenomena kecelakaan di km 90 tol Cipularang ini kemudian digunakan dalam pembelajaran untuk melihat pengetahuan metakognitif siswa (Gambar 6). Pengetahuan metakognitif yang diuji melalui butir soal adalah sub tipe pengetahuan strategis (Da), sementara pengetahuan kognitif $(\mathrm{Db})$ dan pengetahuan diri (Dc) tidak dibahas dalam penelitian ini.

\section{Soal dan Jawaban (Pengetahuan Metakognitif (Da))}

Kamu sedang dalam perjalanan menuju Jakarta dari Bandung, saat itu kamu melewati km 88 jalan tol Cipularang.

Berdasarkan pembelajaran online dan praktikum yang dilakukan, maka : a. Apa yang dapat kalian lakukan jika melalui jalur tersebut agar dapat mengurangi resiko kecelakaan?

$\rightarrow$ Kurangi kecepatan 52.5

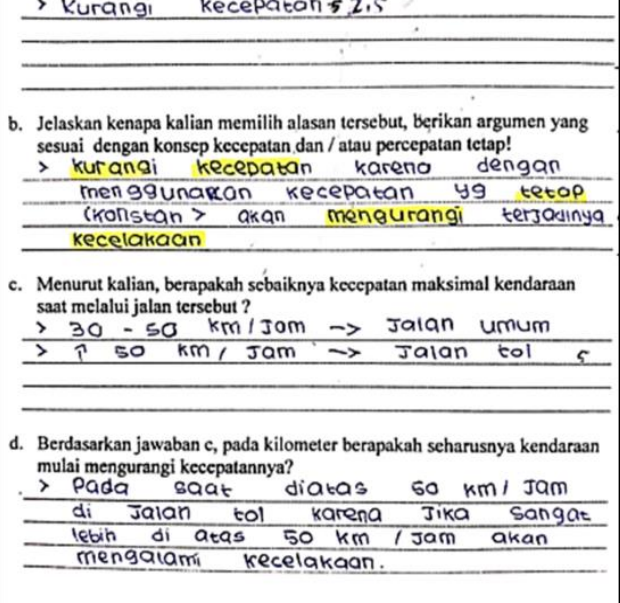

Gambar 6. Butir soal dan cuplikan uraian jawaban siswa untuk melihat pengetahuan metakognitif siswa.

Terdapat empat butir pertanyaan untuk mendeskripsikan pengetahuan strategi (Da) yang menguji kesadaran siswa dalam menguraikan makna pengetahuan 
yang diperoleh dari pengalaman belajar untuk menemukan solusi permasalahan. Praktikum yang dilakukan adalah praktikum Gerak Lurus Berubah Beraturan dengan memodelkan jalan tol Cipularang sebagai sebuah bidang miring.

Tabel 3. Rerata persentase pengetahuan metakognitif (Da) pada kelas kontrol dan kelas eksperimen

\begin{tabular}{ccc}
\hline \multirow{2}{*}{ Butir Soal } & \multicolumn{2}{c}{ Jawaban Benar (\%) } \\
\cline { 2 - 3 } & $\begin{array}{c}\text { Kelas } \\
\text { Kontrol }\end{array}$ & $\begin{array}{c}\text { Kelas } \\
\text { Eksperimen }\end{array}$ \\
\hline $\mathrm{a}$ & 33,3 & 88,9 \\
$\mathrm{~b}$ & 55,6 & 77,8 \\
$\mathrm{c}$ & 88,9 & 88,9 \\
$\mathrm{~d}$ & 88,9 & 100 \\
\hline $\bar{x}_{D c}$ & 66,7 & 88,9 \\
\hline
\end{tabular}

Setelah diberikan perlakuan, terlihat bahwa pengetahuan strategi siswa pada kelas eksperimen lebih tinggi dibandingkan kelas kontrol. Komponen paling menarik adalah pada butir pertanyaan c, yaitu persentase jawaban benar di kelas kontrol maupun kelas eksperimen sama besar. Berdasarkan hasil analisis butir pertanyaan c, dapat diindikasikan bahwa siswa kelas kontrol maupun kelas eksperimen sama-sama telah mengetahui batas maksimum kecepatan kendaraan saat melalui $\mathrm{km} 90$ tol Cipularang. Hal ini dapat diterima, karena fenomena yang digunakan dalam pembelajaran adalah fenomena yang sangat kontekstual dan merupakan trending topic saat itu, sehingga pertanyaan yang digunakan dalam butir c adalah sebuah pertanyaan umum yang dapat dijawab dengan benar oleh mayoritas siswa.

Tabel 4. Rerata persentase kemampuan siswa pada kelas kontrol dan kelas eksperimen

\begin{tabular}{cccc}
\hline \multirow{2}{*}{ Kelas } & \multicolumn{3}{c}{ Jawaban Benar (\%) } \\
\cline { 2 - 4 } & $\begin{array}{c}\text { Konsep- } \\
\text { tual }\end{array}$ & $\begin{array}{c}\text { Prose- } \\
\text { dural }\end{array}$ & $\begin{array}{c}\text { Meta- } \\
\text { kognitif }\end{array}$ \\
\hline $\begin{array}{c}\text { Ekspe- } \\
\text { rimen }\end{array}$ & 88,9 & 77,8 & 88,9 \\
Kontrol & 66,7 & 55.8 & 75,0 \\
\hline
\end{tabular}

Ketiga bentuk pengetahuan yang dianalisis dalam penelitian ini kemudian direkapitulasi pada Tabel 4 untuk menentukan perbedaan persentase kelas kontrol dan eksperimen. Rerata persentase jawaban benar menunjukkan persentase yang lebih tinggi pada kelas eksperimen dibanding kelas kontrol pada setiap tipe pengetahuan. Berdasarkan hasil tersebut, kelas yang diberi perlakuan integrasi model flipped classroom dan PBL menunjukkan tingkat pengetahuan konseptual, prosedural, dan metakognitif yang lebih tinggi dibanding kelas kontrol.

\section{KESIMPULAN}

Berdasarkan hasil penelitian dan analisis data dapat disimpulkan bahwa siswa dengan pembelajaran integrasi flipped classroom dan PBL memiliki kemampuan pengetahuan konseptual, prosedural, dan metakognitif yang lebih baik dibanding kelas control yang tidak diberi treatment. Hal ini disebabkan selama pembelajaran, siswa 
mengalami pembelajaran mandiri, pembimbingan, dan pendalaman dengan berbasis masalah kontekstual dan menantang, yang menghasilkan pengalaman belajar otentik.

\section{DAFTAR PUSTAKA}

Anriani, N., \& Fathurrohman, M. 2019. Pengembangan Lembar Kegiatan Siswa ( LKS ) Berbasis Kompetensi Abad 21 pada Materi Lingkaran Kelas VIII SMP / MTs. Prosiding Sesiomadika, 1(1): 530-537. Retrieved from https://journal.unsika.ac.id/i ndex.php/sesiomadika/article /view/2127

Antika, R. R. 2014. Proses Pembelajaran Berbasis Student Centered Learning (Studi Deskriptif di Sekolah Menengah Pertama Islam Baitul 'Izzah, Nganjuk ). BioKultur, 3(1): 251-263.

Arnata, I. W., Mardana, I. B. P., \& Suwindra, I. N. P. 2020. Pengaruh Model Pembelajaran Problem Based Learning Terhadap Kemampuan Pemecahan Masalah Mitigasi Bencana. Jurnal Pendidikan Fisika Undiksha, 10(1): 36-48. Retrieved from http://journal.um.ac.id/index .php/jptpp/

Azizah, L. M., Poernomo, J. B., \& Faqih, M. I. 2019. Pengembangan Modul Pembelajaran Fisika Kelas XI
MA/SMA Berbasis Guided Inquiry pada Materi Alat-Alat Optik. Physics Education Research Journal, 1(1): 11-20. https://doi.org/10.21580/perj .2019.1.1.4006

Chen, Y.-T., Liou, S., \& Chen, S.-M. 2019. Flipping the procedural knowledge learning - a case study of software learning. Interactive Learning Environments: 1-14. https://doi.org/10.1080/1049 4820.2019.1579231

Damayanti, S. A., Santyasa, I. W., \& Sudiatmika, A. A. I. A. R. 2020. Pengaruh Model Problem Based Learning dengan Flipped Classroom terhadap Kemampuan Berfikir Kreatif. Jurnal Kependidikan Penelitian Inovasi Pembelajaran, 4(1): 8398.

https://doi.org/10.1017/CBO 9781107415324.004

Dewi, G., \& Nur, L. 2014. Pembelajaran Vokal Grup Dalam Kegiatan Pembelajaran Diri di SMPN 1 Panumbangan Ciamis Universitas Pendidikan Indonesia. repository.upi.edu

Fariyani, Q., Rusilowati, A., \& Sugianto. 2017. Four-Tier Diagnostic Test to Identify Miscopnceptions in Geometrical Optics. Unnes Science Education Journal, 6(3): 1724-1729.

Fariyani, Q., Mubarok, F. K., Masfu'ah, S., \& Syukur, F. 2020. Pedagogical Content Knowledge of Pre-service 
Physics Teachers. Jurnal Ilmiah Pendidikan Fisika Al-Biruni, 9(1): 99-107.

https://doi.org/10.24042/jipf albiruni.v9i1.3409

Haryanto, P. C., \& Arty, I. S. 2019) The Application of Contextual Teaching and Learning in Natural Science to Improve Student's HOTS and Selfefficacy. Journal of Physics: Conference Series, 1233(1). https://doi.org/10.1088/17426596/1233/1/012106

Hu, X., Zhang, H., Song, Y., Wu, C., Yang, Q., Shi, Z., Chen, W. 2019. Implementation of Flipped Classroom Combined With Problem-Based Learning: an Approach to Promote Learning About Hyperthyroidism in The Endocrinology Internship. BMC Medical Education, 19(1): 1-8.

https://doi.org/10.1186/s1290 9-019-1714-8

Irawati, E., Kurniawan, W., \& Huda, C. 2019. Kefektifan Pembelajaran Berbantuan Alat Peraga Perpindahan Kalor Secara Konduksi, Konveksi, Dan Radiasi untuk Mendukung Pemahaman Konsep Mahasiswa. Physics Education Research Journal, 1(1): 21.

https://doi.org/10.21580/perj .2019.1.1.3932

Kiernan, L., Ledwith, A., \& Lynch, R. 2017. How Design Education Can Support Collaboration in
Teams. Proceedings of the 19th International Conference on Engineering and Product Design Education: Building Community: Design Education for a Sustainable Future, E and PDE 2017: 14-19.

Klemenčič, M. 2017. From Student Engagement to Student Agency: Conceptual Considerations of European Policies on Student-Centered Learning in Higher Education. Higher Education Policy, 30(1): 69-85.

https://doi.org/10.1057/s4130 7-016-0034-4

Melyana. 2018. Pengaruh Model Problem Based Learning (PBL) Berbantuan Flipped Classroom terhadap Kemampuan Memecahkan Masalah Siswa pada Materi Perubahan Lingkungan (Universitas Muhammadiyah Sukabumi). Retrieved from http://eprints.ummi.ac.id/id/ eprint/537

Oinam, D. S. 2017. StudentCentered Approach to Teaching and Learning in Higher Education for Quality Enhancement. IOSR Journal of Humanities and Social Science, 22(06): 27-30. https://doi.org/10.9790/08372206132730

Olusegun, S. 2015. Constructivism Learning Theory: A Paradigm for Teaching and Learning. IOSR Journal of Research $\mathcal{E}$ Method in Education Ver. I, 5(6): 
2320-7388.

https://doi.org/10.9790/738805616670

Peranginangin, S. A., Saragih, S., \& Siagian, P. 2019. Development of Learning Materials through PBL with Karo Culture Context to Improve Students' Problem Solving Ability and SelfEfficacy. International Electronic Journal of Mathematics Education, 14(2): 265-274. https://doi.org/10.29333/iejm e/5713

Putri, M. D. 2018. Penerapan Model Problem Based Learning Melalui Pendekatan Flipped Classroom Termodifikasi untuk Meningkatkan

Kemampuan Memahami Konsep dan Argumentasi Ilmiah Siswa SMP pada Materi Tekanan ZaT (Universitas Pendidikan Indonesia). Retrieved from http://repository.upi.edu/id/ eprint/37360

Ramadhani, R., Umam, R., Abdurrahman, A., \& Syazali, M. 2019. The Effect Of FlippedProblem Based Learning Model Integrated with LMS-Google Classroom for Senior High School Students. Journal for the Education of Gifted Young Scientists, 7(2): 137-158. https://doi.org/10.17478/jegy s. 548350

Şanli, C. 2019. Investigation of Question Types in High School Geography Coursebooks and Their Analysis in Accordance With The Revised Bloom's
Taxonomy. Ege Coğrafya Dergisi, 28: 111-127.

Serin, H. 2018. A Comparison of Teacher-Centered and StudentCentered Approaches in Educational Settings. International Journal of Social Sciences \& Educational Studies, 5(1): 164. https://doi.org/10.23918/ijsse s.v5i1p164

Singhal, D. D. 2017. Understanding Student- Centered Learning and Philosophies of Teaching Practices. International Journal of Scientific Research and Management, 5: 513-5129. https://doi.org/10.18535/ijsr $\mathrm{m} / \mathrm{v} 5 \mathrm{i} 2.02$

Subagia, M. 2017. Penerapan Model Pembelajaran Flipped Classroom Untuk Meningkatkan Prestasi Belajar Ipa Siswa Kelas X Ap 5 SMK Negeri 1 Amalapura Tahun Ajaran 2016 / 2017. Lampuhyang, 8(2): 14-25.

Taqwa, M. R. A., \& Pilendia, D. 2018. Kekeliruan Memahami Konsep Gaya, Apakah Pasti Miskonsepsi? Jurnal Inovasi Pendidikan Fisika Dan Integrasinya, 01(02): 1-12.

Tari, D. K., \& Rosana, D. 2019. Contextual Teaching and Learning to Develop Critical Thinking and Practical Skills. Journal of Physics: Conference Series, 1233(1). https://doi.org/10.1088/17426596/1233/1/012102

Tuwoso. 2016. The Implementation 
of Constructivism Approach for Physics Learning in Vocational High School. AIP Conference Proceedings, 1778. https://doi.org/10.1063/1.496 5791

Umam, H. I. 2013. Implementasi Strategi

Metakognitif

Pembelajaran

Meningkatkan untuk

Metakognitif dan Prestasi Belajar

Fisika Siswa SMA. Retrieved from

http://repository.upi.edu/id/ eprint/1573

Van Vliet, E. A., Winnips, J. C., \& Brouwer, N. 2015. FlippedClass Pedagogy Enhances Student Metacognition and Collaborative-Learning

Strategies in Higher Education But Effect Does Not Persist (14). https://doi.org/10.1187/cbe.1 4-09-0141

Widari, I., \& Jazadi, I. 2019.
Constructivist Learning

Paradigm in The Introduction to Education Subject. Journal of Education and Learning (EduLearn), 13(1): 57-65. https://doi.org/10.11591/edu learn.v13i1.10424

Wilson, L. O. 2016. Anderson and Krathwohl Bloom's Taxonomy Revised Understanding the New Version of Bloom's Taxonomy. The Second Principle, 1-8. Retrieved from https://quincycollege.edu/co ntent/uploads/Andersonand-Krathwohl_RevisedBlooms-

Taxonomy.pdf\%0Ahttps://the secondprinciple.com/teaching -essentials/beyond-bloomcognitive-taxonomyrevised/\%0Ahttp://thesecond principle.com/teachingessentials/beyond-bloom-cog 